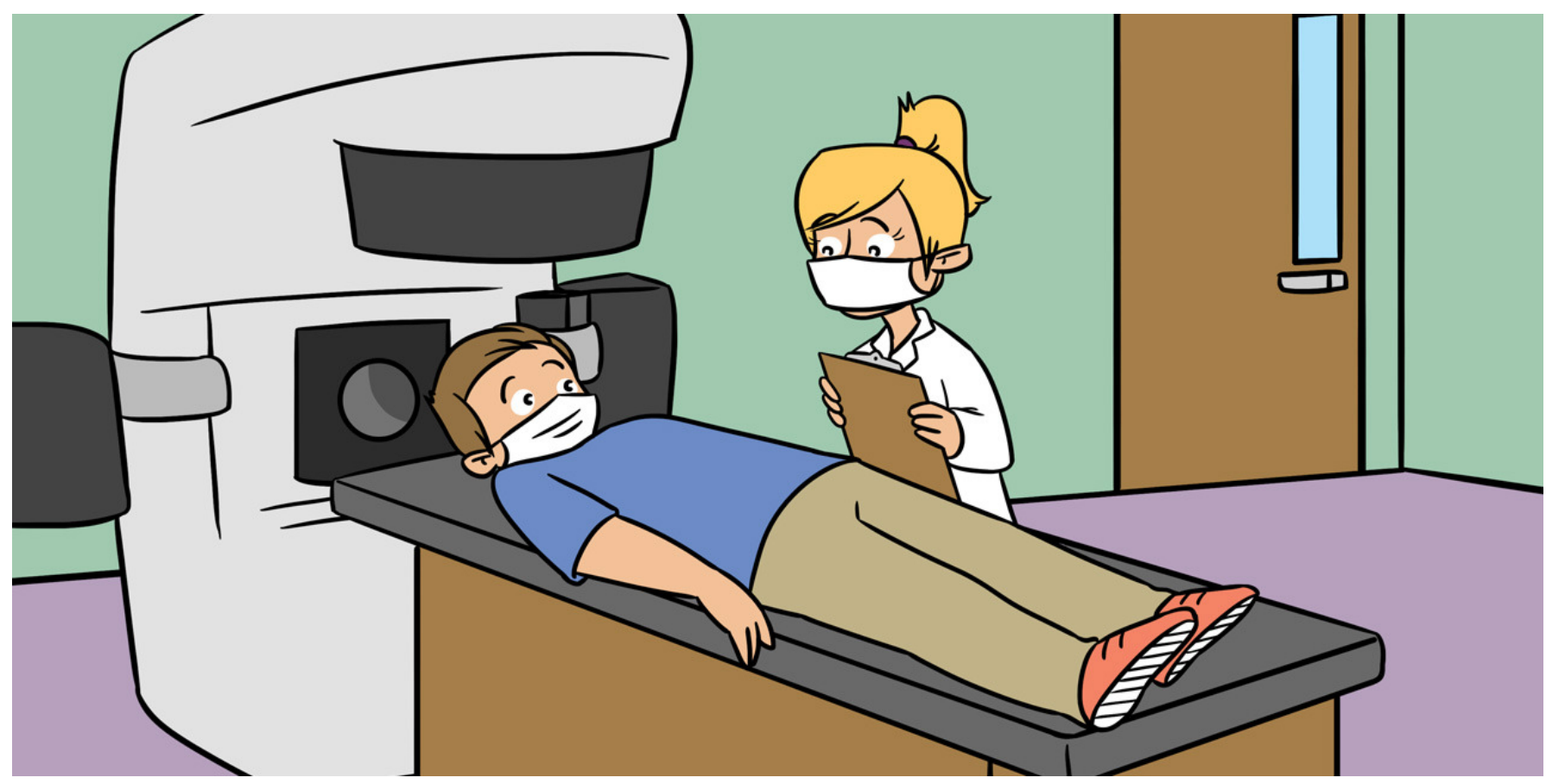

\title{
TREATING CANCER WITH X-RAY RADIATION THERAPY
}

\section{Kristopher A. Lyons, Theodore H. Arsenault and Zi Ouyang *}

Department of Radiation Oncology, University Hospitals Seidman Cancer Center, Cleveland, OH, United States

\section{YOUNG REVIEWERS:}



MANCHESTER

YOUNG

MINDS

AGES: $10-16$

\section{CANCER}

A disease caused by uncontrolled growth and division of abnormal cells.
Radiation therapy is an important cancer treatment. At least half of the cancer patients in the United States receive radiation therapy every year. X-rays are often used in radiation therapy. How are $\mathrm{X}$-rays produced? How do we use X-rays to treat cancer? This article answers these questions and explains the physics behind radiation therapy.

\section{WHAT IS CANCER?}

The human body is made of cells. Normally, cells grow, divide, do their jobs, and eventually die. Cells divide to produce new cells, and the new cells replace the old cells that are dying or dead. A balanced rate of cell replacement is the key to proper organ function, growth, and aging.

For reasons that are not yet clear to scientists, sometimes cells start to divide uncontrollably. Some of these cells become cancer cells. Uncontrollable division of cells can create a solid mass of cells called 
TUMOR

A swelling part of the body of tissue, formed when cells grow and divide more than they should.

DNA

Substance inside a cell that contains instructions for growth, development functions, and reproduction.

MEDICAL LINEAR ACCELERATOR

A machine that uses electricity to generate a stream of fast moving particles to produce radiation to treat cancer.

\section{X-RAY RADIATION}

High-energy light capable of penetrating solids tumor, which can grow and invade other body tissues. Tumors can affect organ function and may lead to death.

Surgery, chemotherapy, and radiation therapy are the main treatments used to fight cancer. Surgery aims to remove the tumor, but other treatments aim to destroy the cancer cells. DNA contains the instructions for life and is present inside most cells, even cancer cells. Destroying the DNA may kill the cell, so many cancer therapies, such as chemotherapy and radiation, focus on destroying the DNA inside cancer cells [1]. Every year, $50-60 \%$ of cancer patients in the United States receive radiation therapy [2]. Radiation can be produced in various ways. One of them is to use a machine called a medical linear accelerator (LINAC), which produces $X$-rays.

\section{HOW ARE X-RAYS PRODUCED?}

Before we go into the details of how a LINAC works, let's talk about electrons. Electrons, together with protons and neutrons, are the basic components of everything that we see: the earth, water, computers, human bodies, and everything else! If we take a wire, like the kind from an old-fashioned light bulb, and heat it, electrons will come off the wire. The wire effectively becomes so hot that electrons "boil off" its surface. Now we have some "free" electrons. Electrons have negative charges, so they are attracted to positive charges. The LINAC uses this property to give electrons lots of energy and make them move at extremely high speeds in an accelerating waveguide. The energy of electrons is measured in electron-volts. The voltage from a typical wall socket in your home ranges from 100 to 240 volts, depending on which part of the world you live in. A LINAC, however, accelerates the electrons to an energy equivalent of millions of volts.

Inside the LINAC, these extremely fast-moving electrons will hit a target, which is usually made of tungsten. Tungsten is a dense metal, packed with protons and electrons. What happens when all those fast-moving electrons hit the tungsten target? They may interact with the protons and electrons of the target and give off energy. Energy has different forms, including light, heat, and speed. Part of the energy created when electrons slam into the tungsten target is emitted in the form of X-ray radiation [3]. Figure 1 shows a diagram of a LINAC, with a patient on the treatment table.

\section{TREATING CANCER WITH X-RAYS}

X-rays are a type of light that cannot be seen by humans the way blue and red light can. Due to their high energy, X-rays can penetrate deeply into-or even go right through-human bodies. Just like clear or partially tinted glasses are transparent to visible light, most parts of the human body are transparent to X-rays. 
Figure 1

Inside a medical linear accelerator (LINAC), electrons are accelerated to extremely high speeds and slammed into a tungsten target. When the electrons hit the tungsten's protons or electrons, these collisions give off energy in the form of $X$-ray radiation. The $X$-rays are directed to the site of the patient's tumor.

\section{Figure 2}

DNA is present in most cells and contains all the instructions for keeping the cell alive and performing its functions. The high energy of radiation can damage the DNA, which can either cause the cell to die immediately or prevent it from dividing to form new cells.
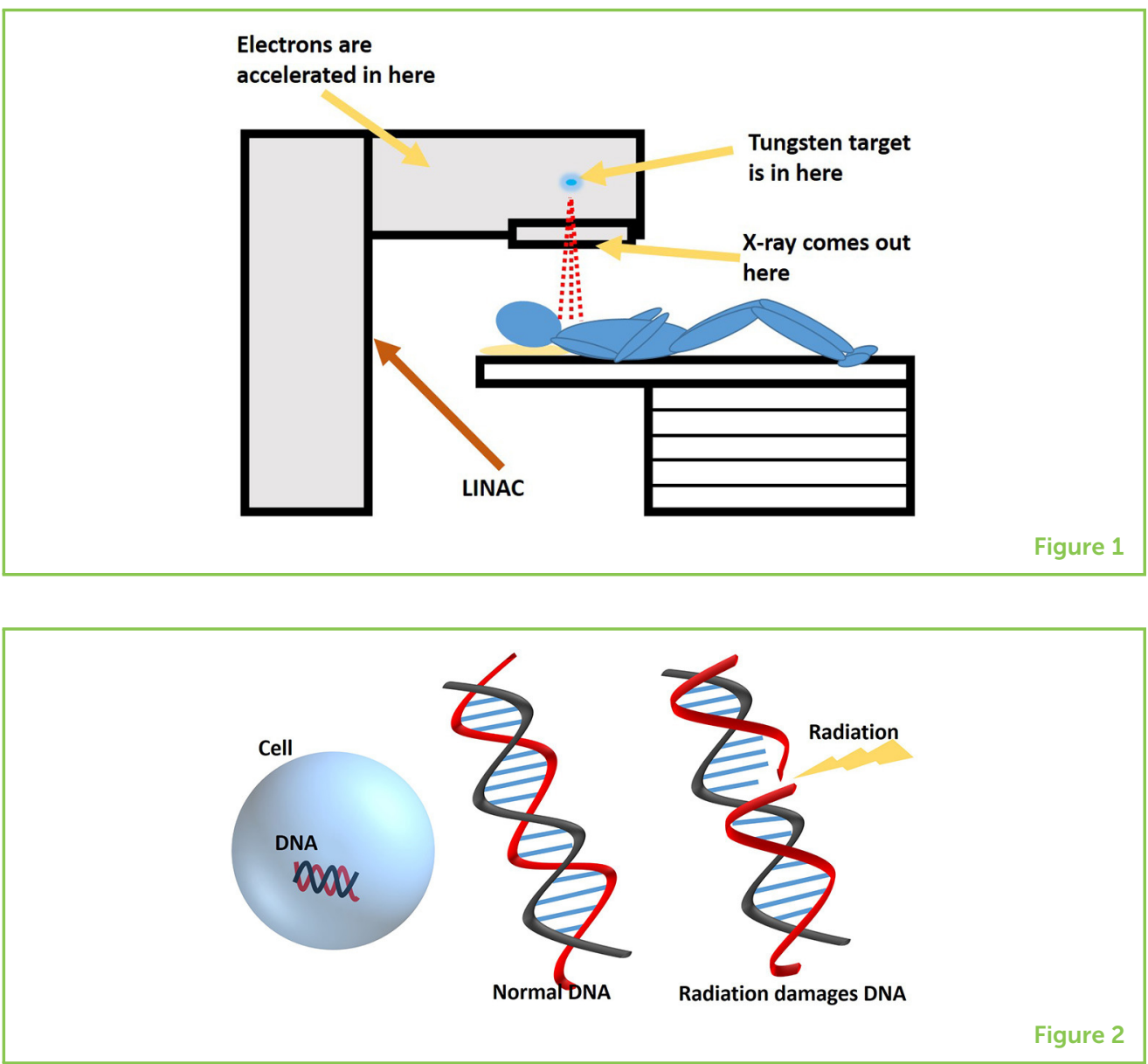

You may have heard that light is both a wave and a particle-and although this might sound confusing, it is true! Light particles are called photons. To help us better understand X-rays, we will have to think of them as particles. Human bodies are almost transparent to X-rays, which means some of the photons go right through human bodies as if nothing is there. Some photons, however, bump into and interact with the protons and electrons of the body. Just like with tungsten in the LINAC, energy is given off when these particles collide with each other. The energy emitted is so high that it can damage the DNA of both normal cells and cancer cells (Figure 2). Once there is enough damage to a cell, it will either die immediately or will not be able to divide to produce new cells.

To treat cancer, we want to kill the cancer cells and protect the normal cells, but X-ray photons cannot tell the difference between the two. How do we solve the problem? First, most cancer cells divide very quickly, while normal cells don't divide as much. During cell division, a cell's DNA is exposed and vulnerable to X-ray damage. Therefore, cancer cells are easier targets for $X$-rays. Depending on the type of cancer, doctors will come up with a specific treatment pattern that will allow the normal cells to remain undamaged or to recover from the treatment. For example, cancers that are located deep inside the 
body receive treatment that is designed so X-rays enter the body from different angles, and the patient receives radiation on different treatment days. By doing this, the X-rays focus on the cancer cells, while the surrounding normal cells get much less damage.

\section{WHAT ARE THE SIDE EFFECTS OF RADIATION THERAPY?}

Because radiation can damage normal cells, there are some side effects related to the treatment. The most common side effects include hair loss and skin discomfort. Patients also get tired easily throughout the treatment. Treating cancer is not easy and most of the time, a combination of treatment methods must be used to achieve the best results. Sometimes, however, cancer treatment may still fail. There are still many unanswered questions in the field of cancer treatment, and doctors and scientists are studying and doing research to continue to find better solutions.

Patients who receive radiation therapy using $\mathrm{X}$-rays produced by a LINAC do not become radioactive-they do not emit radiation. The source of radiation, the LINAC, is always outside the patient's body, which is why radiation will not be emitted from within the patient's body. To treat some types of cancer, instead of using a LINAC, radiation may be given to a patient using an implanted device. In such cases, when the source of radiation is inside the patient, the patient can emit radiation. These patients must usually follow specific instructions from their physicians about how to resume daily life after radiation therapy. For example, some patients may have to wait a few weeks before holding a baby, or may not be able to travel on an airplane without a doctor's letter.

\section{RADIATION THERAPY REQUIRES TEAMWORK}

The production of $x$-rays by the LINAC is an exciting and innovative method to treat cancer, and the technology will continue to evolve and grow in order to benefit patients' lives. Treating cancer with radiation therapy requires teamwork. The radiation oncology team includes many specialists. Doctors, nurses, and radiation therapists see and interact with patients throughout their treatment, while medical dosimetrists create the treatment plans that will be delivered by the LINAC. Medical physicists test and calibrate the LINAC frequently to ensure it is operating properly and safely. In addition, the treatment team includes physician assistants, nurse assistants, social workers, administrative specialists, and others! Each team member has a critical role to play, to make sure that patients receive the best possible treatment. 


\section{REFERENCES}

1. Hall, E. J., and Amato J. G. 2006. Radiobiology for the Radiologist. Philadelphia, PA: Lippincott Williams \& Wilkins.

2. Halperin, E. C., Wazer, D. E., Perez, C. A., and Brady, L. W. 2013. Perez \& Brady's Principles and Practice of Radiation Oncology. Philadelphia, PA: Lippincott Williams \& Wilkins.

3. Khan, F. M., and Gibbons, J. P. 2014. Khan's the Physics of Radiation Therapy. Philadelphia, PA: Lippincott Williams \& Wilkins.

SUBMITTED: 30 October 2019; ACCEPTED: 29 June 2021; PUBLISHED ONLINE: 22 July 2021.

EDITED BY: Bergithe Eikeland Oftedal, University of Bergen, Norway

CITATION: Lyons KA, Arsenault TH and Ouyang Z (2021) Treating Cancer With X-ray Radiation Therapy. Front. Young Minds 9:428516. doi: 10.3389/frym.2021. 428516

CONFLICT OF INTEREST: The authors declare that the research was conducted in the absence of any commercial or financial relationships that could be construed as a potential conflict of interest.

COPYRIGHT () 2021 Lyons, Arsenault and Ouyang. This is an open-access article distributed under the terms of the Creative Commons Attribution License (CC BY). The use, distribution or reproduction in other forums is permitted, provided the original author(s) and the copyright owner(s) are credited and that the original publication in this journal is cited, in accordance with accepted academic practice. No use, distribution or reproduction is permitted which does not comply with these terms.

\section{YOUNG REVIEWERS}

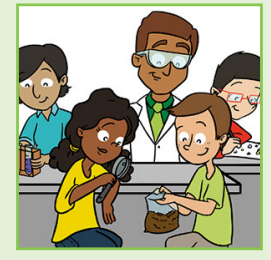

MANCHESTER YOUNG MINDS, AGES: 10-16

We are a group of young people living in greater Manchester and passionate about science and health care!

\section{AUTHORS}

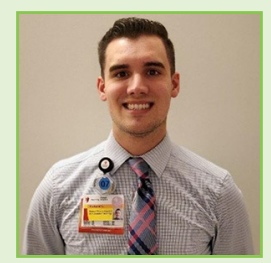

\section{KRISTOPHER A. LYONS}

Hello, my name is Kristopher Lyons; I am currently in my residency training here in Cleveland, $\mathrm{OH}$ to become a medical physicist. Once my training is complete, I will be able to work as a Medical Physicist, and will be able to work on linear accelerators and be actively involved in treatment plans in order to treat cancer. Outside of work, I enjoy the outdoors, reading, and enjoy college and professional sports. 


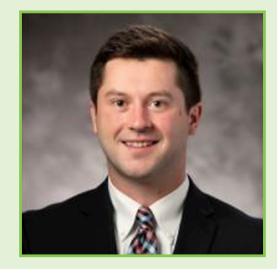

\section{THEODORE H. ARSENAULT}

I am a physicist interested in understanding how photons interact with cells to kill cancer cells. To do this, I use clinical linear accelerators to target cancer cells using high-energy particles. By understanding this biology, my hope is that we can eventually develop effective treatments for different types of cancer. In my free time, I enjoy hiking and playing golf with my friends. Thank you to the Young Reviewers for their feedback and excitement about science!

\section{ZI OUYANG}

I am a medical physicist in the radiation oncology department. I work on the radiation machines to ensure the safety and accuracy of radiation treatment. I help throughout the course of treatment and provide physics consults whenever needed. *zi.ouyang@uhhospitals.org 